Research Article

\title{
Geometric Model for Physical Simulation System of Coal and Gas Outburst
}

\author{
Shutong Zhang (iD \\ School of Traffic and Civil Engineering, Shandong Jiaotong University, Jinan 250357, China \\ Correspondence should be addressed to Shutong Zhang; zstsdust@hotmail.com
}

Received 7 September 2020; Revised 20 October 2020; Accepted 22 October 2020; Published 3 November 2020

Academic Editor: Radoslaw Zimroz

Copyright ( $\odot 2020$ Shutong Zhang. This is an open access article distributed under the Creative Commons Attribution License, which permits unrestricted use, distribution, and reproduction in any medium, provided the original work is properly cited.

\begin{abstract}
The physical simulation system is an important means to study the mechanism of coal and gas outburst. The small- and mediumsized coal and gas outbursts account for the largest proportion in China. So, the paper focuses on small- and medium-sized coal and gas outbursts based on key physical rules and their statistical characteristics. According to the geometric parameters statistical data of more than 100 caverns, the proportion of outburst caverns whose depth is less than $5 \mathrm{~m}$ is $80 \%$, and whose depth is more than $6 \mathrm{~m}$ is $13 \%$. The ratio of depth and cavern outlet's diameter is $2.58-7.31$. There are statistical relationship of 2 times between coal's and cavern's volume, and between gas emission volume per ton and gas content in seam. Then, the cavern of coal and gas outburst is simplified as an ellipsoid, and the shape of cavern outlet is simplified as a circle. The cavern's and the prototype's geometrical parameters of small and medium coal and gas outbursts were deduced. The depth of cavern is $5 \mathrm{~m}$, width is $4 \mathrm{~m}$, and diameter of cavern outlet is $0.68-1.94 \mathrm{~m}$. The depth of coal and outburst prototype is $12.3 \mathrm{~m}$, width is $6.5 \mathrm{~m}$, and diameter of cavern outlet is $0.68 \mathrm{~m}$. In order to guarantee the movement similarity, according to the relationships among statistical data of outburst coal particle's size, cavern outlet's size, and height of tunnel, the minimum cavern outlet's size was calculated. Select 10 times the coal particle's size $(5 \mathrm{~mm})$ as the smallest size. Then, maximum geometric similarity ratio of coal and gas outburst was deduced, and it is 13.6. The minimum geometrical parameters of coal and outburst similar model were obtained. Its depth is $0.9 \mathrm{~m}$, width is $0.48 \mathrm{~m}$, and diameter of cavern outlet is $50 \mathrm{~mm}$. According to the results, the physical simulation system was developed. The results provide support to carry out physical simulation experiment of coal and gas outburst.
\end{abstract}

\section{Introduction}

Since the first recorded coal and gas outburst that occurred in Loire mining areas of France in March 22, 1834, more than 20 countries and regions have experienced coal and gas outburst $[1,2]$. China's first coal and gas outburst occurred in west pit coal roadway face of Fuguo Coal Mining Liaoyuan Coal Mining Bureau in April 20, 1950. Today, according to the statistics, the number of coal and gas outbursts in China accounts for $1 / 3$ of the global total [3]. China has become one of the most affected countries by coal and gas outburst.

At present, comprehensive hypothesis of coal and gas outburst mechanism has been accepted by global scholars. Then, it is considered that the coal and gas outburst is caused by the combined action of gas pressure, in situ stress, and physical and mechanical properties of coal. Based on the "comprehensive hypothesis theory," the global scholars carried out a great deal of studies and build many theories. The physical simulation experiments are an important means to study the mechanism and prevention technology of coal and gas outburst, in which the similar material and physical simulation system are the key factors. Many researchers studied the mechanical characteristics of rock, coal, and similar materials [4-6]. Meanwhile, various physical simulation systems are developed to carry out physical experiments. Ходот et al. had done the one-dimension outburst simulation test firstly. The geometric dimension of the molding model is $0.2 \mathrm{~m} \times 0.6 \mathrm{~m} \times 1.4 \mathrm{~m}$. The hydraulic press can provide a vertical loading pressure of $10 \mathrm{MPa}$, and the sealing pressure can reach 1-2.5 MPa. The experiments were carried out with briquette and $\mathrm{CO}_{2}$, and the results have shown that coal and gas outburst will occur only under high gas pressure gradient [7]. Kravchenko used 
coal samples of $0.2 \mathrm{~m} \times 0.04 \mathrm{~m} 0.04 \mathrm{~m}$ and $\mathrm{CO}_{2}$ to carry out experiments with gas pressure of $2-5 \mathrm{MPa}$. The failure wave velocity of coal samples was measured by an oscilloscope [8]. Yartsev carried out the experiments with coal samples with a diameter of $56 \mathrm{~mm}$ and a height of $100 \mathrm{~mm}$ and pressure of 0.5-4.0 MPa [9]. Kuroiwa and Tashiro used a cylindrical device with a volume of $120 \mathrm{~cm}^{3}$ to simulate the coal and gas outburst tests with briquette coal samples and $\mathrm{CH}_{4}$ [10]. Alekseev et al. developed a triaxial stress test equipment. The maximum pressure of the device is $600 \mathrm{MPa}$, the adsorption equilibrium pressure is $15 \mathrm{MPa}$, and the coal sample size is $60 \mathrm{~mm} \times 60 \mathrm{~mm} \times 60 \mathrm{~mm}$ [11]. Bodziony et al. carried out experiments with a cylindrical device. Its diameter is $97.4 \mathrm{~mm}$ and length is $281 \mathrm{~mm}$. Deng Quanfeng, Luan Yongcai, and Wang Youan developed a one-dimensional outburst simulation test system. The vertical and lateral pressures are provided by $100 t$ and $500 t$ material testing machines. The coal sample container of the system is a cylinder with an inner diameter of $200 \mathrm{~mm}$, and the mouth is a circle with a diameter of $20 \mathrm{~mm}$. Through 12 outburst tests using the system, it was concluded that the minimum gas pressure of outburst increases linearly with the increasing of coal strength [12]. Zhou and He developed a three-dimensional loading rheological test system, in which the coal sample container is a cylinder with an inner diameter of $50 \mathrm{~mm}$ and a length of $100 \mathrm{~mm}$, and the loading is provided by a creep press [13]. Nelieki and Topolnicki developed a test device with a diameter of $96.4 \mathrm{~mm}$ and a length of $300 \mathrm{~mm}$. The outburst test of briquette samples made from $0.2 \mathrm{~mm}$ pulverized coal and adsorbed gas of $\mathrm{N}_{2}$ or $\mathrm{CO}_{2}$ was simulated [14]. Jiang Chenglin and Yu Qixiang developed a onedimensional outburst simulation test system. The vertical pressure of the system is provided by a $500 t$ testing machine. The coal sample container is a cylinder with an inner diameter of $442 \mathrm{~mm}$, and its outlet is an adjustable round shape with a maximum diameter of $200 \mathrm{~mm}$. The coal and gas outburst tests were carried out with the system, and the hypothesis of spherical shell instability was obtained [15]. Cai carried out three-dimensional simulation test of coal and gas outburst. The size of outburst simulation module (length $\times$ width $\times$ height) is $225 \mathrm{~mm} \times 225 \mathrm{~mm} \times 187.5 \mathrm{~mm}$, and the factors influencing outburst strength are obtained [16]. Norbert Skoczylas developed a two-dimensional loading outburst simulation test equipment. The coal sample chamber is cylindrical, with an inner diameter of $48 \mathrm{~mm}$, a length of $110 \mathrm{~mm}$, and a protrusion size of $0.78 \mathrm{~mm}^{2}-21.84 \mathrm{~mm}^{2}$. The experiments were carried out with uniaxial compressive strength of 1.8-17.2 MPa and gas pressure of 1.4-31.7 $\mathrm{MPa}$. The relationships between uniaxial compressive strength, gas pressure, and outburst were obtained [3]. In addition, the research teams of Anhui University of Science \& Technology and Chongqing University developed three-dimensional coal and gas outburst model test systems and carried out plenty of experiments with different conditions. These researches' results improved the prevention and treatment level of the disaster. The former physical simulation systems have the variety of dimensions of similar models. Because of less study on the similar model, this results in the decline of similar degree.
Aimed at the shortages of physical simulation systems, the paper puts forward a geometric model for physical simulation system through studying the similar model's dimension of small and medium coal and gas outbursts according to their characteristics of outburst cavern, gas emission, and coal particle size based on dominant physical law in coal and gas outburst. The study focuses on prototype geometric parameter of coal and gas outburst and development of physical similar simulation system, including depth and width, and diameter of cavern outlet. The results can provide a high similar degree system to study the mechanical processes for coal and gas outburst.

\section{Mechanical Mechanism of Coal and Gas Outburst}

2.1. Evolution Process of Coal and Gas Outburst. Mechanical mechanism theory of coal and gas outburst is derived from the "comprehensive hypothesis theory." The views of the theory are that there exist four stages of preparation, initiation, development, and termination in the process of coal and gas outburst. And under certain conditions, there also exist several pauses and re-initiation process in the stage of development [17-19]. The evolution processes of coal and gas outburst are shown in Figure 1, in which the thick solid line expresses the inevitable phenomenon and the thick dashed line expresses the possible phenomena.

In the stage of preparation, balance of original in situ stress in working face is destroyed by mining activity. It causes rebalancing of the situ stress. During the process, coal and rock mass around the working face are destroyed. So, there forms in situ stress concentration area and bearing pressure limited equilibrium area appears in front of the working face's coal wall. The quasi-static deformation and damage of coal and rock provide mechanical failure conditions for initiation of coal and gas outburst.

In the stage of initiation, accumulation of deformation and fracture of coal or rock mass is achieved to certain critical conditions or there exists outside disturbing load suddenly; coal and rock are destroyed and lose their bearing capacity. During the process of destruction, elastic potential energy and gas internal energy stored in coal and rock are released rapidly and lead to the destroyed coal and rock being thrown out. Then, there forms the initial outburst cavern.

In the stage of development, the coal and rock mass with high in situ stress and gas pressure around the outburst cavern is suddenly exposed after initiating of coal and gas outburst. Stress loaded in coal wall of outburst cavern is suddenly removed and then gas rapidly desorbs and flows into the cavern. It forms benefit condition for coal mass's failure. Under the composited action of in situ stress and gas pressure, coal seam is broken and thrown out rapidly. Meanwhile, the outburst cavern is gradually expanded.

In the stage of pause and re-initiation, after the development stage there is no condition to meet the coal destruction, so coal destruction pauses. The reason why coal destruction is paused is that there forms support action in cavern wall caused by accumulation of coal and gas, and 


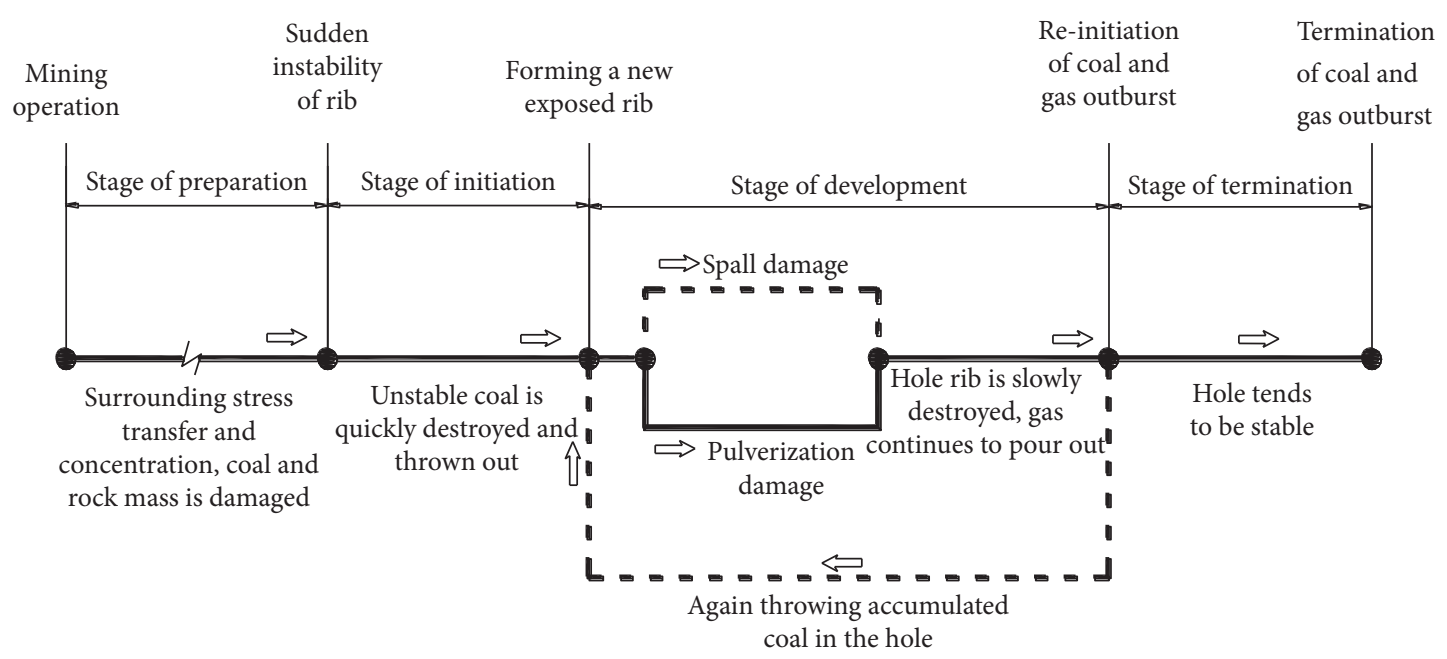

\begin{tabular}{ll} 
& Inevitable phenomenon \\
\hline - _ _ - - Possible phenomenon
\end{tabular}

FIgUre 1: Phase division of coal and gas outburst [17].

unloading effect is weakened, caused by slow damage of cavern wall. Then, the coal and rock mass around the outburst cavern will continue quasi-static deformation and emit gas into cavern. When the gas pressure in the cavern increases to a certain value, the fractured coal and rock will be thrown out again, and the coal and rock of cavern wall will be destroyed continuously. It results in a new occurrence of coal and gas outburst.

In the stage of termination, if there is not enough gas pressure to throw out the fractured coal and rock again after the stage of development, the re-initiation of coal and gas outburst cannot appear also. The outburst cavern becomes stable and the coal and gas outburst is terminated.

2.2. Dominant Physics Laws in Coal and Gas Outburst. The views of mechanical mechanism theory of coal and gas outburst are that coal and gas outburst are of continuous or alternating appearances of three dominant phenomena as follows [17]:

(1) Static deformation and destruction of coal seam in the stage of preparation.

The in situ stress balance of original formation is destroyed in the process of mining in workface. There forms support pressure area in front of workface, and part of coal seam is destroyed. It is the stage of preparation of coal and gas outburst. The deformation and destruction processes are quasi-static.

(2) Fracture of gassy coal seam in the stages of initiation and development.

The main phenomenon is the rapid broken gassy coal seam in the stage of development. It is caused by the sudden changing of in situ stress and sudden exposing of gassy coal seam to high pressure. The essence of the broken seam is that the tensile stress concentration results in fissure expansion. And the tensile stress concentration caused in situ stress and gas pressure in caverns and cracks tip of coal seam.

(3) Movement of broken coal and gas flow in mining space.

During the outburst, there forms separation phenomenon where coal particle sizes distribute large to small with the near to far distance from outburst cavern because of outburst broken coal and gas flow's movement and deposition in mining space. Also, there appear damaging shock waves in the initial of the outburst.

\section{Statistical Characteristics of Coal and Gas Outburst}

3.1. Shape and Geometric Parameters of Coal and Gas Outburst Cavern. After the coal and gas outburst, there is a cavern in coal and rock mass along with coal, and rock and gas are thrown into mining space. According to statistical research, cavern of coal and gas outburst general has a small opening and a big cavity. Shapes of caverns are pear-shaped, tongue-shaped, bottle inversion-shaped, bifurcation-shaped, and so on $[18,20,21]$. Caverns of coal and gas outburst have different geometric parameters. The caverns' characteristics geometric parameters of more than 100 coal and gas outbursts that occurred during tunnel excavating in Chongqing district are shown in Table 1.

Depth of outburst cavern along the strike is the important parameter. In Table 1, it is shown that the proportion of outburst caverns whose depth is less than $5 \mathrm{~m}$ is $80 \%$, and whose depth is more than $6 \mathrm{~m}$ is $13 \%$, in Chongqing area.

Typical coal and gas outburst has the characteristics of small opening and big cavity. The statistical geometric parameters of small and medium coal and gas outburst' cavern are shown in Table 2. 
TABLE 1: Geometric parameters statistical data of more than 100 caverns that occurred during tunnel excavating in Chongqing district [22].

\begin{tabular}{lccccc}
\hline Height $(\mathrm{m})$ & Number (time) & Width $(\mathrm{m})$ & Number (time) & Depth (m) & Number (time) \\
\hline$<2$ & 47 & $<2$ & 56 & 28 & $2 \sim 4$ \\
$2 \sim 5$ & 49 & $2 \sim 4$ & 8 & $4 \sim 5$ & 42 \\
$5 \sim 10$ & 15 & $4 \sim 6$ & 1 & $5 \sim 6$ & 8 \\
$>10$ & 7 & $>6$ & - & $>6$ & 15 \\
- & - & - & 93 & & 117 \\
Total & 118 & & & & \\
\hline
\end{tabular}

TABLE 2: Caverns' geometric parameters of small and medium coal and gas outbursts.

\begin{tabular}{|c|c|c|c|c|c|c|}
\hline Location & $\begin{array}{l}\text { Coal seam } \\
\text { thickness }(\mathrm{m})\end{array}$ & $\begin{array}{l}\text { Coal seam } \\
\text { angle }\left(^{\circ}\right)\end{array}$ & $\begin{array}{c}\text { Orifice } \\
\text { diameter }(\mathrm{m})\end{array}$ & $\begin{array}{l}\text { Cavern } \\
\text { depth }(m)\end{array}$ & $\begin{array}{l}\text { Maximum } \\
\text { width }(\mathrm{m})\end{array}$ & $\begin{array}{l}\text { Outburst coal (rock) } \\
\text { quality }\left(\mathrm{kg} \times 10^{3}\right) / \\
\text { type }\end{array}$ \\
\hline $\begin{array}{l}\text { Main inclined shaft contact lane of } \\
\text { Xinjiang Tianfu Electric power (Group) } \\
\text { Limited Company Honggou Mine }\end{array}$ & 2.98 & 40 & 2 & 8 & 5 & 210/medium \\
\hline $\begin{array}{l}21202 \text { auxiliary air return coal roadway in } \\
\text { Zunyi Coal Mine Buzheng mine }\end{array}$ & 1.2 & 28 & 2.1 & 7.45 & 3.5 & /small \\
\hline $\begin{array}{l}+310 \text { m level south tenth cross-cut with } \\
4 \text { th coal seam of Lindong Coal Mine }\end{array}$ & 2.0 & 25 & 2.1 & 6 & 2 & 130/medium \\
\hline $\begin{array}{l}3301 \text { haulage gateway driving workface of } \\
\text { Panlong Coal Mine }\end{array}$ & 1.4 & 12 & 1.3 & 9.5 & 6 & 280/medium \\
\hline $\begin{array}{l}\text { Main drift cross-cut with C5 coal seam of } \\
\text { Da Zhuba Coal Mine }\end{array}$ & 1.6 & 32 & 2.3 & 6.5 & 4.5 & 203/medium \\
\hline $\begin{array}{l}\text { Main haulage gateway of Ci Wazi Coal } \\
\text { Mine }\end{array}$ & - & 28 & 3.1 & 8 & 4 & $79 /$ small \\
\hline $\begin{array}{l}\text { 1st district return airway raise roadway of } \\
\text { Gushu Coal Mine }\end{array}$ & 2.29 & 45 & 3.8 & 12 & 8 & 600/big \\
\hline
\end{tabular}

3.2. Gas Emission Quantity. Plenty of gas is emitted in the process of coal and gas outburst. The gas concentration will exceed normal state in coal mine for several days because the stacked coal continually desorbs large amounts of gas. The gas emission quantity depends on outburst scale and gas content of coal seam. According to standard, coal and gas outburst has the characteristic where unit gas emission quantity of outburst coal is greater than or equal to $30 \mathrm{~m}^{3} / \mathrm{t}$, or more than twice the content of local coal seam.

\subsection{Volume Relationship between Outburst Coal Quantity and} Cavern. The volume of outburst cavern is always smaller than that of outburst coal and rock. According to the statistics, volume of outburst cavern is half of outburst coal volume normally. But the volume ratio is $1 / 10$ in some special coal and gas outbursts $[18,22]$.

3.4. Size of Outburst Coal Particle. The outburst coal particle has the form of block or is granular with some size. Statistical size data of outburst coal out of the outburst cavern is shown in Table 3.

\section{Geometric Parameter of Coal and Gas Outburst Similar Model}

Generally, most of the coal and gas outbursts are small and medium. So, the data about similar model in this paper is derived from the statistics of small and medium coal and gas outbursts.

4.1. Geometric Parameter of Coal and Gas Outburst Cavern. Outlet of coal and gas outburst cavern is simplified to a circle in this paper. The outburst cavern is described by height, width, and depth. According to the data in Table 1, it is analyzed that depth of the coal and gas outburst that happened in China is less than $5 \mathrm{~m}$, and the width is less than $4 \mathrm{~m}$ [17].

Height of outburst cavern has relation to thickness and dip angle of coal seam. The height of similar model is decided by the coal seam. In China, coal mining is mostly in medium thickness coal seam. So, the thickness is less than $3.5 \mathrm{~m}$ normally.

According to the statistical data of outburst cavern's outlet in Table 2, size of outburst cavern's outlet varies with the outburst scales. Among the lager coal and gas outbursts, outlet size of outburst cavern that occurred in coal roadway heading face is limited by the height of coal seam thickness, but there is no limit to the width of coal seam. So, there forms the outburst cavern of its width larger than height. As seen in Table 2, the ratio of depth and cavern outlet's diameter is $2.58 \sim 7.31$. When the depth of coal and gas outburst is $5 \mathrm{~m}$, cavern outlet's diameter is $0.68-1.94 \mathrm{~m}$. It is fit to the thickness $(1.3 \sim 3.5 \mathrm{~m})$ of the main mining coal seam in China.

Analyzing the above, the geometric parameters of typical small and medium coal and gas outburst are shown in Table 4 and Figure 2. 
TABLe 3: Statistical sizes data of outburst coal particle's out of the cavern [17].

\begin{tabular}{|c|c|c|c|c|c|c|}
\hline & Size range $(\mathrm{mm})$ & $<0.1$ & $0.1 \sim 1$ & $1 \sim 5$ & $5 \sim 10$ & $>10$ \\
\hline \multirow{5}{*}{$\begin{array}{l}\text { Mass percent } \\
(\%)\end{array}$} & 4th coal seam $+90 \mathrm{~m}$ level of Yu Tianbao Coal Mine & 3.6 & 38.0 & 31.0 & 17.6 & 9.8 \\
\hline & 5th cross-cut $\mathrm{K} 2$ coal seam cut of $+280 \mathrm{~m}$ level in Zhong Liangshan Coal Mine & 25.4 & 26 & 27.6 & 1.0 & 20.0 \\
\hline & $\begin{array}{c}\text { South-west } 5 \text { th cross-cut K10 coal seam cut of }+280 \mathrm{~m} \text { level in Zhong Liangshan Coal } \\
\text { Mine }\end{array}$ & 3.5 & 30.4 & 30.5 & 19.4 & 16.2 \\
\hline & $\begin{array}{c}\text { Southwest half pass } 4 \text { th cross-cut K10 coal seam cut of }+280 \mathrm{~m} \text { level in Zhong Liangshan } \\
\text { Coal Mine }\end{array}$ & 6.6 & 27.5 & 16.9 & 18.2 & 30.8 \\
\hline & 6th coal seam $-100 \mathrm{~m}$ level of Nantong Coal Mine & 1.1 & 11.9 & 23.9 & 23.5 & 39.5 \\
\hline
\end{tabular}

TABLE 4: Geometric parameter of cavern and outlet.

\begin{tabular}{lcr}
\hline Depth & Width & Diameter of cavern outlet \\
\hline 5 & 4 & $0.68 \sim 1.94$ \\
\hline
\end{tabular}

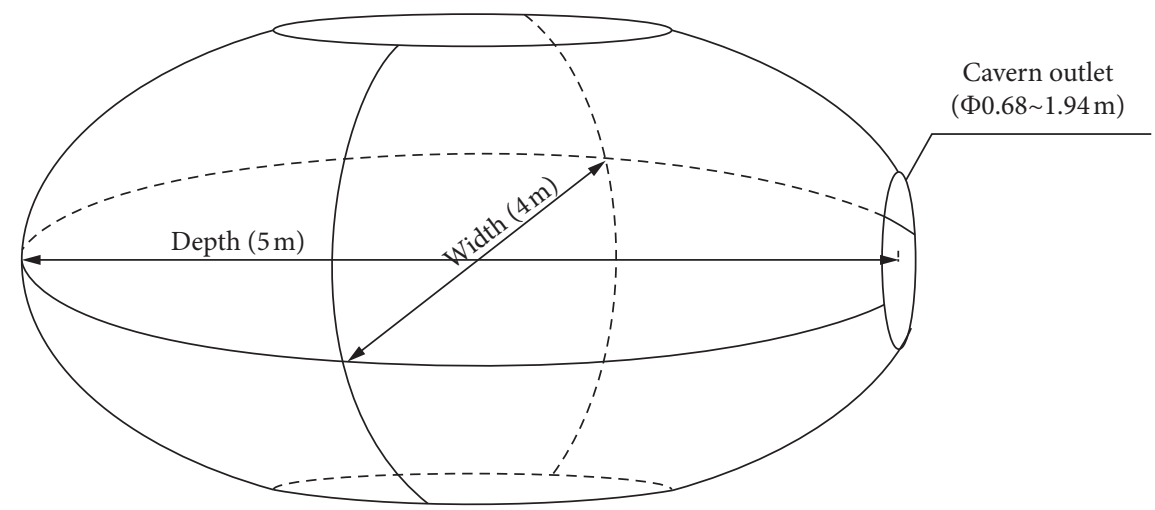

Figure 2: Sketch map of coal and outburst cavern.

Height of coal and gas outburst is depended on thickness of coal seam. So, the height of outburst cavern is not considered in Table 4.

\subsection{Prototype Geometric Parameter of Coal and Gas Outburst.} Geometric parameter of outburst cavern is different from coal and gas outburst prototype's because outburst cavern is produced by coal and gas outburst. In the process of coal and gas outburst, there is coal and rock mass of big area participating in the outburst and not only that of the outburst cavern area. So the coal and outburst prototype contains coal and rock mass of cavern area and the surrounding influenced area.

(1) Prototype geometric parameters deduced by the volume relation between outburst cavern and outburst broken coal.

Volume of outburst cavern is always smaller than that of outburst broken coal. According to statistic data of more than 30 outburst caverns that occurred in Zhong Liangshan Coal Ming, Yu Tianbao Coal Ming, and Donglin Coal Ming located in Chongqing district, the volume ratio of outburst cavern and outburst broken coal is $1 / 2[18,22]$. The outburst cavern is equivalent to an elliptic cylinder whose major axis is $5 \mathrm{~m}$ and minor axis is $4 \mathrm{~m}$. The prototype of coal and gas outburst is considered as an elliptic cylinder too. When the coal gas outburst occurs in small and medium thick coal seam, the height $h$ is assumed to be the thickness of the coal seam. Analyzing the statistics in Table 2, ratio of cavern's depth and width becomes larger with the increase of cavern's depth. The ratio is 1.44-2.13, and the average ratio is 1.89 . In this paper, the volume ratio of outburst cavern and outburst broken coal is $1 / 2$, so the ratio of prototype's major and minor axis is $1.89: 1$. It is calculated that the participating coal and rock mass is in the area of length $8.7 \mathrm{~m}$, width $4.6 \mathrm{~m}$, and height $h$.

(2) Prototype geometric parameters deduced by the relation between gas emission quantity of unit mass coal and gas content of coal seam.

According to statistics, gas emission quantity of unit mass coal is more than twice gas content of coal seam in most coal and gas outbursts because of the gassy coal seam 
surrounding outburst cavern desorbs and is emitted to the roadway [17]. According to standard, coal and gas outburst has the characteristic where unit gas emission quantity of outburst coal is greater than or equal to $30 \mathrm{~m}^{3} / \mathrm{t}$, or more than twice the content of local coal seam. In order to keep similar gas emission, the gas quantity derived from the influenced coal seam should be taken into account. In order to simplify calculation, the ratio of gas emission quantity of unit mass and gas content of coal seam is determined to be 2 times in this paper. It is assumed that gassy coal of influenced area desorbs all gas in the occurrence process or later in coal and gas outburst. So, the influenced area of coal seam is twice the outburst cavern area. Based on the above condition, the ratio of prototype's major axis and minor axis is $1.89: 1$. So the participating coal and rock mass is in the area of length $12.3 \mathrm{~m}$ and width $6.5 \mathrm{~m}$.

So, the minor prototype geometric parameters of typical small and medium coal and gas outburst are shown in Table 5.

4.3. Geometric Parameters of Coal and Gas Outburst Physical Similar System. For the convenience of test, the size of physical similar system is usually smaller than that of the prototype. But, size of outburst cavern outlet should fit the size of outburst coal particles. If the size of outburst coal particles is close to or larger than the size of outburst cavern outlet, the coal particles will block outburst cavern outlet and will result in the failure of occurrence of test. From Table 3, the mass proportion of coal particles size of $5 \mathrm{~mm}$ is more than $64 \%$. The similar material which is used to carry out similar simulation test in laboratory has the characteristics of better uniformity, lower strength, and smaller coal particles than coal seam, and the proportion of coal particles of size $5 \mathrm{~mm}$ would be larger than $64 \%$. So, the size of 10 times $5 \mathrm{~mm}$ is chosen as the minor size of outburst cavern outlet. Then, the minor size of outburst cavern outlet is $50 \mathrm{~mm}$. It is calculated that the maximum geometric similarity ratio of the physical similar simulation model is 13.6 .

In order to keep the similar movement of coal particles in roadway, the size of similar simulation roadway should be greater than the size of outburst coal particles. So, the size of 10 times $5 \mathrm{~mm}$ is chosen as the size of similar simulation roadway. According to the rule of height of road way in "Mine Safety Regulations" of China, the height of roadway is chosen as $2.0 \mathrm{~m}$. It is calculated that the maximum geometric similarity ratio of the physical similar simulation model is 20 .

So, the maximum geometric similarity ratio of the physical similar simulation model is 13.6. The minimum geometric parameters of similar simulation model are shown in Table 6.

\section{Development of Physical Similar Simulation System}

5.1. Sealed Cabin. The sealed cabin is used to make gassy coal seam model. It has the size of $1.5 \times 0.8 \times 0.8 \mathrm{~m}$
TABLE 5: Minor prototype geometric parameters of typical small and medium coal and gas outburst (m)*

\begin{tabular}{lcc}
\hline Depth & Width & Diameter of cavern outlet \\
\hline 12.3 & 6.5 & 0.68 \\
\hline
\end{tabular}

${ }^{*}$ Height of coal and gas outburst depends on thickness of coal seam.

TABLE 6: Minimum geometric parameters of similar simulation model (m).

\begin{tabular}{lcc}
\hline Depth & Width & Diameter of cavern outlet \\
\hline 0.90 & 0.48 & 0.05 \\
\hline
\end{tabular}

(length $\times$ width $\times$ height) which is developed according to the geometric similarity ratio 8 . And the maximum size of outburst cavern outlet is $300 \mathrm{~mm}$. At present, within the mining depth of $1000 \mathrm{~m}$, the gas pressure of coal seam is less than $6 \mathrm{MPa}$ normally. So, the pressure of working pressure is designed to be $6 \mathrm{MPa}$ [23]. The opening method of outburst cavern outlet is positive-pressure blasting using rupture disc. The similar simulation system can carry out simulation test of different sizes through changing the sizes of model and outburst cavern outlet. The sealed cabin is shown in Figure 3.

At present, the structural form of roadway is trapezoid and arch usually in coal mine. And its height is about $2.5 \mathrm{~m}$. For ease of manufacture, section of simulated roadway is simplified to a square. The geometric similarity ratio is chosen as 8 . So, the size of the simulated roadway section is $300 \mathrm{~mm}$. It is fit to the size of outburst cavern outlet.

5.2. Simulated Roadway. The simulated roadway is consisted by straight pipes (length of $1 \mathrm{~m}$ and $1.5 \mathrm{~m}$ ), bending pipes (turning angles of $10^{\circ}, 20^{\circ}$, and $90^{\circ}$ ), and three-way pipes. So, the different combination methods of pipes can simulate different forms of roadways. The pipes are shown in Figure 4.

5.3. Mechanical Loading System. Most of the coal mining depth is less than $1000 \mathrm{~m}$ in China. The rock mass average density is $2.5 \times 10^{3} \mathrm{~kg} / \mathrm{m}^{3}$. So, it is calculated that the in situ stress is about $25 \mathrm{MPa}$ in the depth of $1000 \mathrm{~m}$. Because the bearing area is $1.2 \mathrm{~m}^{2}(1.5 \mathrm{~m} * 0.8 \mathrm{~m})$, the mechanical loading system is designed such that the vertical loading is $3 \times 10^{6} \mathrm{~kg}$ and the horizontally symmetrical loading is $2 \times 10^{6} \mathrm{~kg}$. And the structural form of loading system is of frame type.

To prevent the impact of test system during the test, the system rigidity is designed to be more than $3 \times 10^{10} \mathrm{~N} \cdot \mathrm{m}^{-1}$.

Mechanical loading system is shown in Figure 5.

5.4. Data Acquisition System. Monitoring equipment uses NI PXI data acquisition system and phantom v210 highspeed camera. Based on NI PXI data acquisition system, the data acquisition software is developed. The system can 


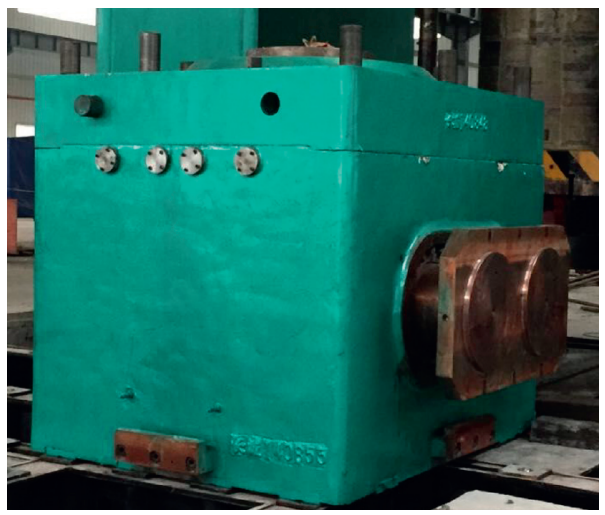

FIGURE 3: Sealed cabin.

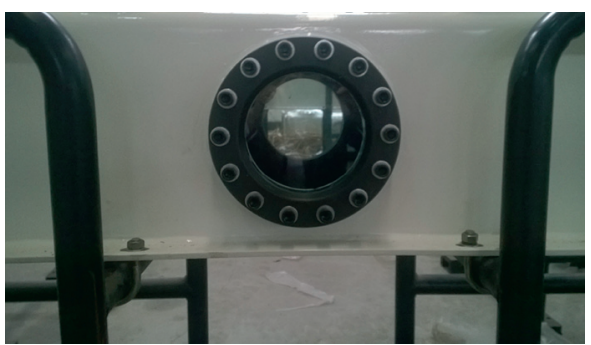

(a)

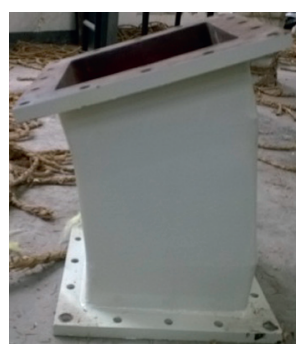

(b)

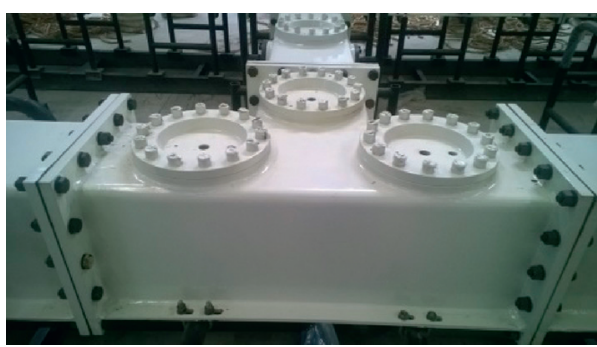

(c)

FIgURE 4: Simulation roadway. (a) Straight pipe. (b) Bending pipe. (c) Three-way pipe.

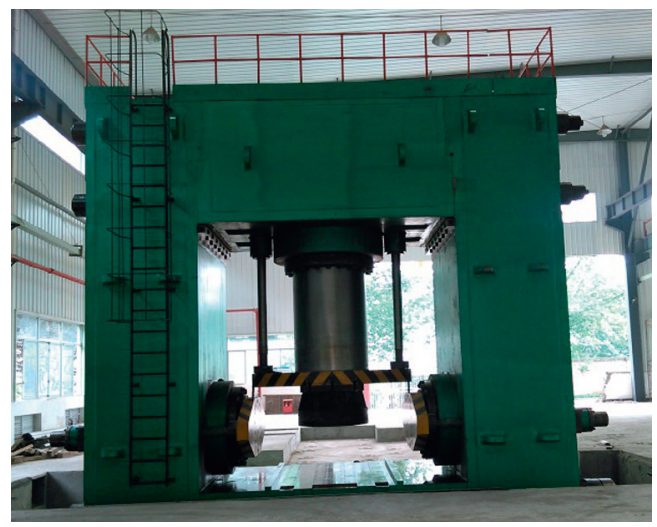

(a)

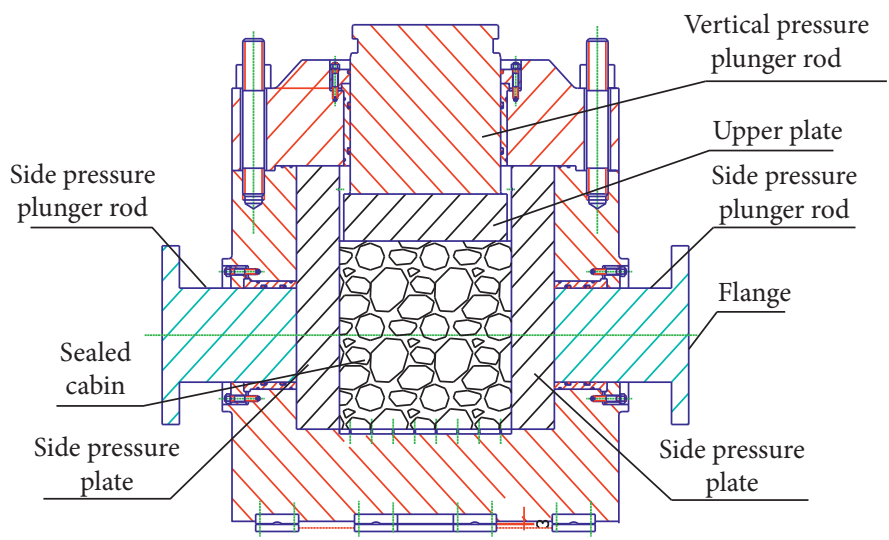

(b)

FIgURE 5: Mechanical loading system. (a) Frame-type mechanical loading system. (b) Loading mode of sealed cabin.

collect such parameters of coal and gas outburst as in situ stress, gas pressure, temperature, velocity of stress wave, shock wave, wind speed, oxygen concentration, carbon dioxide concentration, and image of the cavern process. Data acquisition system is shown in Figure 6.
5.5. Dust Collector. The dust collector is comprised of air inlet, dust cleaning window, multi-stage vibration bag dust collecting device, and air outlet. The dust collector is shown in Figure 7. It is used for clearing dust produced in test and keeping the environmental protection. 


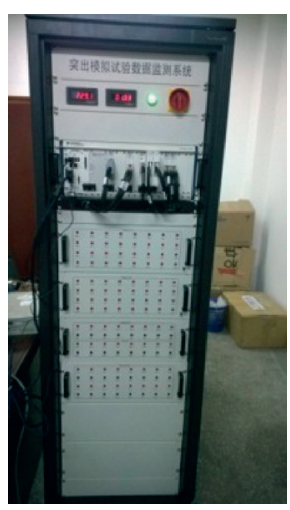

(a)

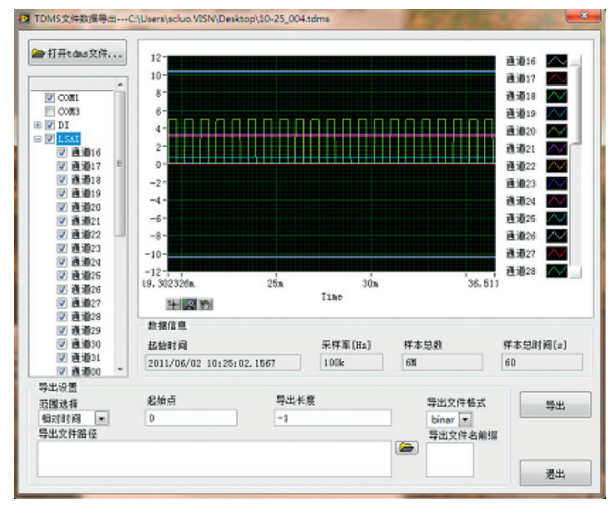

(b)

FIgURE 6: Data acquisition system. (a) Hardware. (b) Software.

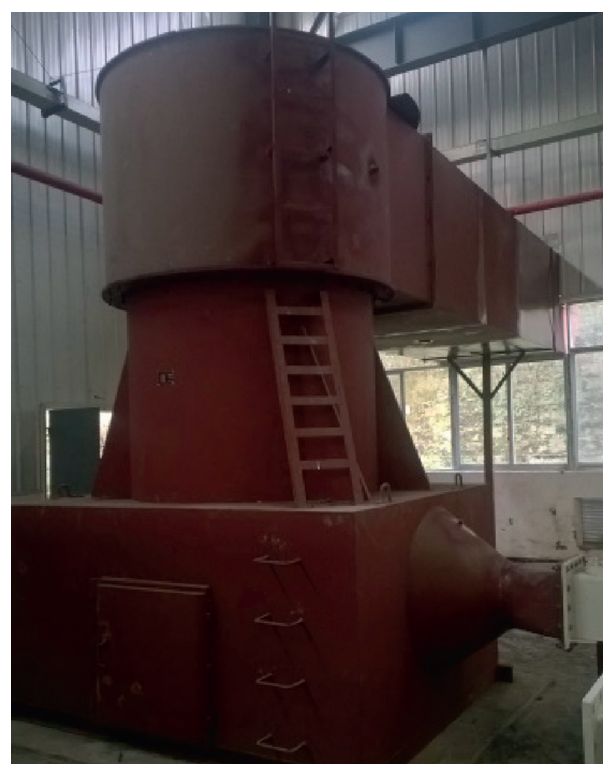

Figure 7: Dust collector.

\section{Conclusion}

Based on the statistical data of small and medium coal and gas outbursts, the geometric sizes of the prototype and similar model of medium and small coal and gas outburst are theoretically deduced. Then, the physical simulation system is developed. Conclusions are obtained as follows:

(1) The cavern of small and medium coal and gas outburst is equivalent to an elliptic cylinder. The cavern's major axis is $5 \mathrm{~m}$ and minor axis is $4 \mathrm{~m}$. Height depends on the thickness of the coal seam. Diameter of the cavern outlet is $0.68-1.94 \mathrm{~m}$.

(2) With the relations between outburst broken coal and rock volume, gas emission quantity of unit mass, and gas content of coal seam, the minimum geometric size of coal and gas outburst prototype is deduced.
The depth is $12.3 \mathrm{~m}$, width is $6.5 \mathrm{~m}$, and diameter of cavern outlet is $0.68 \mathrm{~m}$.

(3) According to the size relations between coal particle and outburst cavern outlet, and between coal particle and roadway, the maximum geometry similarity ratio of prototype and model is 13.6. The minimum geometry depth is $0.90 \mathrm{~m}$, width is $0.48 \mathrm{~m}$, and diameter of cavern outlet is $0.05 \mathrm{~m}$.

(4) The physical simulation system is developed. Geometry size of sealed cabin is $1.5 \times 0.8 \times 0.8 \mathrm{~m}$ (length $\times$ width $\times$ height). Its gas bearing capacity is $6 \mathrm{MPa}$, and maximum diameter of outburst cavern outlet is $0.3 \mathrm{~m}$. The section of simulated roadway is square and its edge length is $0.3 \mathrm{~m}$. The vertical loading is $3 \times 10^{6} \mathrm{~kg}$, and the horizontally symmetrical loading is $2 \times 10^{6} \mathrm{~kg}$. The system rigidity is more than $3 \times 10^{10} \mathrm{~N} \cdot \mathrm{m}^{-1}$. 


\section{Discussion}

Coal and gas outburst is the result of comprehensive action of in situ stress (including tectonic stress) and gas and coal physical and mechanical properties. The occurrence mechanism is complex. The existing research methods of coal and gas outburst mechanism are mainly divided into three types. In the early stage, scholars analyzed the phenomenon of coal and gas outburst and deduced the outburst mechanism and put forward the hypothesis of gas leading role and in situ stress leading role hypothesis. With the deepening of understanding of coal and outburst, scholars have carried out research on outburst mechanism by means of energy theory, mechanical theory, and numerical simulation, which promotes the understanding of disasters and the improvement of prevention and control technology. At present, due to the need of safety production, the mechanism of outburst has been studied qualitatively and quantitatively. Because it is difficult to achieve the field test, the similar material simulation test has become an effective method to study the outburst criterion quantitatively. However, most of the similar coal seam models in the former test system are cylindrical, and the mechanical loading is mainly one-dimensional. Although some tests were carried out with threedimensional simulation system, the size of coal sample is small. So, most of the similar experiments have low degree of similarity.

On the basis of previous studies, the geometry size of outburst simulation test system is obtained, and the test system is developed based on the analysis of coal and gas outburst data in the paper. The results improve the similarity of simulation system and promote the progress of physical similar simulation experiment. However, due to the limited amount of data, the geometric size of the similar model proposed in this paper does not fit all conditions, and the effect of tectonic stress is not considered alone. In the following research, scholars will continue to improve the present simulation test system and strive to restore the real coal and gas outburst process.

\section{Data Availability}

The data used to support the findings of this study are available from the corresponding author upon request.

\section{Disclosure}

The authors would like to declare on behalf of their coauthors that the work described was original research that has not been published previously and not under consideration for publication elsewhere, in whole or in part. All the authors listed have approved the manuscript that is enclosed. Meanwhile, the founding sponsors had no role in the design of the study; in the collection, analyses, or interpretation of data; in the writing of the manuscript; and in the decision to publish the results.

\section{Conflicts of Interest}

The authors declare no conflicts of interest, and the manuscript is approved by all authors for publication.

\section{Acknowledgments}

This research was supported by Key R\&D Program of Shandong Province, China (Grant no. 2019GSF111051), Shandong Provincial Natural Science Foundation, China (Grant no. ZR2018LE009), and the PhD Start-up Fund of Shandong Jiaotong University, China.

\section{References}

[1] X.-J. Li and B.-Q. Lin, "Status of research and analysis on coal and gas outburst mechanism," Coal Geology \& Exploration, vol. 38, no. 1, pp. 7-13, 2010, in Chinese.

[2] T. Deng, Experiment of Coal Containing Gas under the Condition of Unloading Confining Pressure Research on Relief Scope of Upper Protective Seam Mining, Chongqing University, Chongqing, China, 2012, in Chinese.

[3] N. Skoczylas, "Laboratory study of the phenomenon of methane and coal outburst," International Journal of Rock Mechanics and Mining Sciences, vol. 55, pp. 102-107, 2012.

[4] P. Małkowskia, Ł. Ostrowskia, and J. Brodnyb, "Analysis of Young's modulus for carboniferous sedimentary rocks and its relationship with uniaxial compressive strength using different methods of modulus determination," Journal of Sustainable Mining, vol. 17, no. 3, pp. 145-157, 2018.

[5] Q. Hu, S. Zhang, G. Wen, L. Dai, and B. Wang, "Coal-like material for coal and gas outburst simulation tests," International Journal of Rock Mechanics and Mining Sciences, vol. 74, pp. 151-156, 2015, in Chinese.

[6] N. Skoczylas, "Coal seam methane pressure as a parameter determining the level of the outburst risk-laboratory and in situ research," Archives of Mining Sciences, vol. 57, no. 4, pp. 861-869, 2012.

[7] A. A. Skochinski, "Communication of the initiation of a sudden outburst of gas and coal in the model in outburst laboratory of the Institute of Mining of an SSS," UGOL, vol. 10, p. 39, 1953.

[8] V. S. Kravchenko, "On the nature and mechanism of sudden outbursts of gas and coal," Nauchnye Soobshcheniya Instituta Gornogo Dela Im A. A. Skochinskogo, vol. 6, pp. 101-108, 1955.

[9] V. A. Yartsev, "Crushing of coal in sudden drop of gas pressure,” UGOL, vol. 5, pp. 35-36, 1958.

[10] T. Kuroiwa and T. Tashiro, "Experimental study on coal pulverization and gas emission in a moment of outbursts of gas and coal," Journal of the Mining Institute of Japan, vol. 76, no. 862 , pp. 227-230, 1960.

[11] C.-H. Zhang and Z.-G. Liu, "Review and prospect on coal and gas outburst simulation experiment in laboratory," China Safety Science Journal, vol. 21, no. 3, pp. 48-53, 2011, in Chinese.

[12] Q.-F. Deng, Y.-X. Luan, and Y.-A. Wang, "Coal and gas outbursts similar simulation test," Safety Coal Mining, vol. 20, no. 11, pp. 5-10, 1989, in Chinese.

[13] S.-N. Zhou and X.-Q. He, "Rheological hypothesis of coal and gas outburst mechanism," Journal of China University Mining \& Technology, vol. 19, no. 2, pp. 1-8, 1990, in Chinese.

[14] A. Nelieki and J. Topolnicki, "Experimental stand for the investigation of outbursts of porous materials saturated with gas," Archives of Mining Science, vol. 39, no. 3, pp. 301-312, 1994.

[15] C.-L. Jiang and Q.-X. Yu, "Spherical shell lossing stability hypothesis of coal and gas outburst mechanism," Safety Coal Mining, no. 2, pp. 17-25, 1995, in Chinese. 
[16] C.-G. Cai, "Experimental study on 3-D simulation of coal and gas outbursts," Journal of China Coal Society, vol. 29, no. 1, pp. 66-69, 2004, in Chinese.

[17] Q.-T. Hu and G.-C. Wen, Mechanical Mechanism of Coal and Gas Outburst, Science Press, Beijing, China, 2013, in Chinese.

[18] Q.-T. Hu, Study on the Mechanical Mechanism of Coal and Gas Outburst and its Application, China University of Mining \& Technology, Beijing, China, 2007, in Chinese.

[19] H.-W. Jin, Research on the Failure Mechanism of Coal in the Developmental Stage of Coal and Gas Outburst, China Coal Research Institute, Beijing, China, 2012, in Chinese.

[20] C.-M. Wang, Z. Wang, Y.-P. Liang et al., "Formation mechanism of caverns in progress of coal and gas outburst," Mining Safety \& Environment Protection, vol. 35, no. 4, pp. 60-62, 2008, in Chinese.

[21] C.-G. Cai and Y.-A. Wang, "Qualitative and quantitative analysis of general regularity of coal and gas outburst," China Safety Science Journal, vol. 14, no. 6, pp. 109-112, 2004, in Chinese.

[22] B.-F. Yu, "Discussion on the mechanism of coal and gas outburst," Coal Science and Technology, vol. 8, pp. 34-42, 1979, in Chinese.

[23] Editorial Board, Technical Manual of Comprehensive Gas Control in Coal Mine, Jilin Audio Visual Publishing Hous, Jilin, China, 2003, in Chinese. 